\title{
Changes in the Energy Consumption in EU-27 Countries
}

\section{Vladimír Hajko ${ }^{1}$}

\begin{abstract}
The complete decomposition method is applied to changes in energy consumption in the countries of EU-27. This method decomposes the changes in energy use into three different effects: a change in energy consumption due to an increase of economic activity (the activity effect), a change in energy consumption due to a relative increase of significance of a country in the group (the structure effect) and a change in energy consumption due to a change of energy efficiency measured as energy intensity (the intensity effect). The results confirm that there is a difference in development of these effects between the old (EU-15) and the new member countries. The results show that the activity effect is the most significant effect in old member countries (EU-15), and is on average 1.13 times higher than in new member countries. The intensity effect is the main diversifying factor between the two groups and the most significant effect for the new member countries. The intensity effect is almost universally negative in all countries, and compensates for the other effects. Because of the importance of the effect, energy intensity convergence is examined. It is found that even by the "rough" distinction between the new and the old member countries, the convergence in energy intensity in new member countries can be found (in the old member countries there is no energy intensity convergence).
\end{abstract}

Key words: Decomposition analysis; Energy use; Energy intensity; EU-27

JEL Classification: O13, Q43

\section{Introduction}

After the collapse of the Eastern Bloc and its centrally planned economies, its former members have gone through significant transitions from their previous rather underdeveloped states. While the economic levels of these states, many of which are now members of the European Union are not yet on par with original EU countries, it is to be expected, that even though being very heterogeneous group, there was a different development in the transition countries than in the "old" EU countries.

Technological underdevelopment was one of the many deficiencies of countries with centrally planned economies. With the absence of entrepreneurship, these countries lacked skills, technology and capital to match their capitalist counterparts. Since energy

\footnotetext{
${ }^{1}$ Department of Economics, Faculty of Economics and Administration, Masaryk University, Lipová 507/41a, Brno, Czech Republic. Tel: +420732737843. E-mail address: vladimir.hajko@mail.muni.cz
} 
use plays an important role in virtually every economic activity, it is, to a certain extent ${ }^{2}$, a common proxy of development both in the economic structure and efficiency.

The 2004 and 2007 enlargement that expanded the EU by 12 countries mostly from the former Eastern bloc, and (if compared with the original EU-15) also with a rather low economic level as indicated by GDP per capita, the one obvious differentiation is to observe "new" ${ }^{3}$ and "old"4 member countries separately.

The analysis of the suspected different patterns of development in energy use between the original EU-15 members and the new member countries is the object of this article. The grounds for the analysis of the change in energy use are provided by the results of the complete decomposition method. This method provides greater insight into how and why has the energy use changed.

This insight is provided by decomposing the change in energy consumption to three different effects: activity effect, structure effect and intensity effect. As indicated in the model specification, the essence is to measure an impact of change in one of the factors while keeping the other ones fixed on values of base year.

By doing so, the activity effect captures the change in energy consumption due to the overall increase of economic activity while keeping the energy intensities and economic structure of the countries fixed. The change in energy consumption caused by the change in the share of activity relative to the overall activity of the aggregate ${ }^{5}$ is called the structure effect ${ }^{6}$. Finally, the intensity effect represents a change in energy consumption due to a change of energy efficiency (measured as energy intensity).

\footnotetext{
${ }^{2}$ Mainly due to the long-run character of extensive capital investments, the development in energy sectors exhibits sometimes significant inertia

3 "New member countries" being Bulgaria, Cyprus, Czech Republic, Estonia, Hungary, Latvia, Lithuania, Malta, Poland, Romania, Slovakia and Slovenia

4 "Old member countries" being Austria, Belgium, Denmark, Finland, France, Germany, Greece, Ireland, Italy, Luxembourg, Netherlands, Portugal, Spain, Sweden and United Kingdom

${ }^{5}$ In this case, the EU-27 is taken as the aggregate. It is possible to perform the analysis in relation to the aggregate of the world economy; however, due to the fact of comparing to a much larger base of the world GDP, the structure effect is then rendered rather unsignificant and might be even considered superfluous. Though the impact of the different aggreagte selection on the results is not as pronounced with the two other effects, the reader should be aware the choice of the aggregate $Q$ affects the computations, as follows from the model specification.

${ }^{6}$ Thanks to a suggestion of an anonymous referee, it might prove useful to add a note regarding understanding of structure effect: If one would consider undertaking the decomposition analysis for a single country, the economic structure of the country might be represented by what is commonly referred to as economic sectors: primary (production of raw materials), secondary (production of goods), tertiary (production of services) sometimes even quaternary (research and education), or maybe even in finer subdivisions like distinguishing transport from other services etc. In such case, the structure effect would indeed represent changes in energy consumption resulting from changes in what is commonly referred to as the structure of an individual economy. For example, we would expect the structural effect to be a significant factor in explanation of rise of energy consumption, if we observed e.g. a significant increase of industrial production and transportation. On the contrary, we could observe a low contribution of the structure effect even if the overall economic development (and energy consumption) would go up if there were no large shifts in the structure.
} 
The decomposition method itself (the overview of the application of the method can be found e.g. in Ang and Zhang (2000) covering 124 studies) has been widely used as a tool to bring more insight into energy use analyses (especially when analyzing the energy consumption within a country). If applied to the groups of countries, it would capture similar information as analysis within a country. However, instead of sectors of an economy, individual countries will be considered.

As indicated above, the usual approach of the energy decomposition handles the problem by quantifying contributions of three factors - activity, structural, and intensity effect.

Since the results show that the intensity effect is the most significant difference between the development in the old and the new member countries, in a short detour on energy intensity convergence I examine whether these two groups converge to each other in their energy efficiency (as measured by energy intensity ${ }^{7}$ ), i.e. whether it is reasonable to assume that differences between energy efficiencies should diminish.

Therefore, the goal of this article is to test the hypothesis that there is an observable difference in the energy use development between the old (EU-15) and the new member countries (i.e. the rest of EU-27) by applying the complete decomposition model to the EU-27 countries in the time period of 1990-2008 and examining the differences in the effects.

Another hypothesis is that despite the expected gradual and general improvement of technology, there exists a convergence in energy efficiency between the new and the old member countries. This means to verify whether the new member countries apply the new methods and technologies (and replace the old capital stock) in their energy efficiency investments on greater scale than the old member countries and therefore converge to the levels of energy efficiency of the "more developed" (measured by GDP per capita) countries of EU-15.

The structure of the article follows this pattern. At first, decomposition model is presented and applied to the EU-27 countries in the time period 1990-2008. Afterwards,

However, for this analysis, one considers as the economy not just one country but the EU-27 aggregate, and consider the different countries instead of the individual sectors or subsectors of the economy (e.g. instead of "one way of producing the output", say mining or agriculture, we now talk e.g. about Poland, and instead of say the industrial production we now talk e.g. about Germany). Structural effects shows how energy consumption would change, if EU-27 as a whole produced the same output as in the base year "differently". If readers wish so they may consider this effect under a somewhat less confusing name, e.g. "country effect".

${ }^{7}$ Please note the distinction between the energy intensity indicator and the intensity effect. The energy intensity indicates how much energy it takes to produce a unit of GDP, here measured in tones oil equivalent per constant 1,000 USD of the year 2000. The (energy) intensity effect measures how has the energy consumption changed, therefore is measured in units of oil equivalent (in this article either in megatons oil equivalent (Mtoe) or in \% when this change (in Mtoe) is divided by the base year energy consumption (in Mtoe). Readers should be aware that while the approach used here, i.e. energy:GDP ratio, is probably the most common, it is not without criticism and there are still methodological issues on how to aggregate energy use and measure the energy efficiency or energy intensity. For further discussion see e.g. Patterson (1996) and Cleveland, Kaufmann and Stern (2000). 
I examine energy intensity convergence, namely the beta and sigma convergence of energy intensity. In the last chapter, conclusions of these parts are then summarized.

The World Bank was the data source for the analysis, the time period covers the years 1990-2009. However, due to insufficient data regarding energy use in 2009 in Bulgaria, Cyprus, Estonia, Latvia, Lithuania, Malta, Romania and Slovenia, the results for 2009 are incomplete. These countries, and by extension the aggregate of EU-27, are therefore covered only up to the year 2008. All the tables and figures are the results of my own calculations.

The country selection is concededly not without controversy, as the EU-27 presents very heterogeneous group, and given the time frame in the case of new member states, it was without any doubt also affected by the transformation processes following the transition to planned economy. Nevertheless, apart from the convergence goal, the recent trend in European Union of addressing the energy policy on the supranational level indicates that there is a growing link between energy policies in these countries, and an analysis within this group may be viable option.

\section{Model}

\section{Energy consumption}

In essence, an application of the index numbers, the traditional approach (sometimes called "traditional Laspeyres index method" (Ang and Liu (2007)) to the decomposition analysis was to compute the contribution of each of the aforementioned factors separately.

The basic relation of change of energy consumption between two years is:

$$
E=Q * I=Q^{*} \sum_{i} \frac{E_{i} Q_{i}}{Q_{i} Q}=Q^{*} \sum_{i} I_{i} * S_{i}
$$

,where

$E$ is overall energy consumption, and $E_{i}$ is the consumption in sector $i$

$Q$ is overall economic activity, and $Q_{i}$ is the economic activity in sector $i$

$I$ is overall energy intensity, and $I_{i}$ is the energy intensity in sector $i$

$S_{i}$ is the share of the activity of sector $i$ on the overall economy activity

Energy consumption in year $t$ can be then written as:

$$
E^{t}=Q^{t} \sum_{i} I_{i}^{t} S_{i}^{t}
$$

and in the base year 0 as: 


$$
E^{0}=Q^{0} \sum_{i} I_{i}^{0} S_{i}^{0}
$$

The activity effect can then be stated as:

$$
Q_{\text {effect }}=\left(Q^{t}-Q^{0}\right) \sum_{i}\left(I_{i}^{0} S_{i}^{0}\right)
$$

The structural effect as:

$$
S_{\text {effect }}=Q^{0} \sum_{i} I_{i}^{0}\left(S_{i}^{t}-S_{i}^{0}\right)
$$

And the intensity effect as:

$$
I_{\text {effect }}=Q^{0} \sum_{i}\left(I_{i}^{t}-I_{i}^{0}\right) S_{i}^{0}
$$

The total effect is then:

$$
\Delta E \approx Q_{\text {effect }}+S_{\text {effect }}+I_{\text {effect }}
$$

However, if we use the "traditional" method approach, we are facing the problem of the unexplained residual - the residual in the country $i$ represents the difference between actual and explained change, with often significant magnitude (Ang and Liu (2007)).

While some studies omit the residual completely, or prefer the appealing simplicity of the traditional model even at the cost of only partial explanation, in this case some preliminary calculations indicate that a more complex model of complete decomposition might be more appropriate (e.g. using the incomplete decomposition for the period $1990 / 2008$ indicates that the average residual accounts to the magnitude of approximately $-620 \%$ of the actual changes ${ }^{8}$ and almost $16 \%$ of the cumulative sum of the effects). Furthermore, Ang and Zhang (2000) suggest either the logarithmic mean Divisia index or the refined Laspeyres index method as the preferred choices for the decomposition method, as these possess several desirable properties (e.g. being zerovalue robust and passing both time-reversal and factor-reversal test (for a more comprehensive discussion of the properties of different methods, see Ang and Zhang (2000) and Fisher (1972)).

The approach of this paper follows the methodology proposed by Sun (1998), i.e. the influence of the three aforementioned factors is attributed equally to the three main effects using the principle of "jointly created and equally distributed", thus "refining" the Laspeyres index method and satisfying the desirable properties mentioned by Ang and Zhang (2000).

The general method of complete decomposition using the principle of jointly created and equally distributed is as follows.

\footnotetext{
${ }^{8}$ Since the effects compensate for each other, the incomplete decomposition model predicts much greater changes in energy consumption than what actually happened
} 
In a two-factor model: assuming that $A=x y$, we can calculate the change in $A$, $\Delta A$ by:

$$
\Delta A=A^{t}-A^{0}=x^{t} y^{t}-x^{0} y^{0}=X_{\text {effect }}+Y_{\text {effect }}
$$

which can be decomposed to :

$$
\Delta A=\left(x^{t}-x^{0}\right) y^{0}+\left(y^{t}-y^{0}\right) x^{0}+\left(x^{t}-x^{0}\right)\left(y^{t}-y^{0}\right)
$$

In three-factor model: assuming that $A=x y z$, we can calculate the change in $A, \Delta A$ by:

$$
\Delta A=A^{t}-A^{0}=x^{t} y^{t} z^{t}-x^{0} y^{0} z^{0}=X_{\text {effect }}+Y_{\text {effect }}+Z_{\text {effect }},
$$

so the $\Delta A$ can be decomposed to :

$$
\begin{aligned}
\Delta A= & \left(x^{t}-x^{0}\right) y^{0} z^{0}+\left(y^{t}-y^{0}\right) x^{0} z^{0}+\left(z^{t}-z^{0}\right) x^{0} y^{0} \\
+ & \frac{1}{2}\left(x^{t}-x^{0}\right)\left(\left(y^{t}-y^{0}\right) z^{0}+\left(z^{t}-z^{0}\right) y^{0}\right) \\
+ & \frac{1}{2}\left(y^{t}-y^{0}\right)\left(\left(x^{t}-x^{0}\right) z^{0}+\left(z^{t}-z^{0}\right) x^{0}\right) \\
+ & \frac{1}{2}\left(z^{t}-z^{0}\right)\left(\left(x^{t}-x^{0}\right) y^{0}+\left(y^{t}-y^{0}\right) x^{0}\right) \\
& +\left(x^{t}-x^{0}\right)\left(y^{t}-y^{0}\right)\left(z^{t}-z^{0}\right)
\end{aligned}
$$

In general, $\mathrm{N}$-factor model:

$$
\begin{gathered}
A=x_{1} x_{2} \ldots x_{n} \\
\Delta A=x_{1}^{t} x_{2}^{t} \ldots x_{n}^{t}-x_{1}^{0} x_{2}^{0} \ldots x_{n}^{0}
\end{gathered}
$$

can be decomposed to $\Delta A=n$ terms with one order of $\Delta\left(\Delta x_{i}, i=1,2, \ldots n\right)$ $+\frac{n \times(n-1)}{2 !}$ terms with two orders of $\Delta\left(\Delta x_{i} \Delta x_{j}, i \neq j\right)+\frac{n \times(n-1) \times(n-2)}{3 !}$ terms with three orders of $\Delta\left(\Delta x_{i} \Delta x_{j} \Delta x_{k}, i \neq j \neq k\right)+\ldots+$ one term $\frac{n \times(n-1) \times(n-2) \ldots \times 2}{n !}$ with $n$ orders of $\Delta\left(\Delta x_{i} \Delta x_{2} \ldots \Delta x_{n-1} \Delta x_{n}\right)$.

For further discussion of the derivation, please see Sun (1998) and Sun (1996)). Using the aforementioned principle, the complete decomposition of the energy consumption 8 
model therefore attributes the previously unexplained combined effects in the residual to the individual effects:

$$
\begin{aligned}
& Q_{\text {effect }}=\left(Q^{t}-Q^{0}\right) \sum_{i}\left(I_{i}^{0} S_{i}^{0}\right) \\
& +\frac{1}{2}\left(Q^{t}-Q^{0}\right) \sum_{i}\left(I_{i}^{0}\left(S_{i}^{t}-S_{i}^{0}\right)+S_{i}^{0}\left(I_{i}^{t}-I_{i}^{0}\right)\right) \\
& +\frac{1}{3}\left(Q^{t}-Q^{0}\right) \sum_{i}\left(I_{i}^{t}-I_{i}^{0}\right)\left(S_{i}^{t}-S_{i}^{0}\right) \\
& S_{\text {effect }}=Q^{0} \sum_{i} I_{i}^{0}\left(S_{i}^{t}-S_{i}^{0}\right) \\
& +\frac{1}{2} \sum_{i}\left(S_{i}^{t}-S_{i}^{0}\right)\left(I_{i}^{0}\left(Q^{t}-Q^{0}\right)+Q^{0}\left(I_{i}^{t}-I_{i}^{0}\right)\right) \\
& +\frac{1}{3}\left(Q^{t}-Q^{0}\right) \sum_{i}\left(I_{i}^{t}-I_{i}^{0}\right)\left(S_{i}^{t}-S_{i}^{0}\right) \\
& I_{\text {effect }}=Q^{0} \sum_{i}\left(I_{i}^{t}-I_{i}^{0}\right) S_{i}^{0} \\
& +\frac{1}{2} \sum_{i}\left(I_{i}^{t}-I_{i}^{0}\right)\left(S_{i}^{0}\left(Q^{t}-Q^{0}\right)+Q^{0}\left(S_{i}^{t}-S_{i}^{0}\right)\right) \\
& +\frac{1}{3}\left(Q^{t}-Q^{0}\right) \sum_{i}\left(I_{i}^{t}-I_{i}^{0}\right)\left(S_{i}^{t}-S_{i}^{0}\right)
\end{aligned}
$$

Substituting of the individual effects leads to the expression:

$$
\begin{aligned}
\Delta E=( & \left.Q^{t}-Q^{0}\right) \sum_{i}\left(I_{i}^{0} S_{i}^{0}\right) \\
& +Q^{0} \sum_{i} I_{i}^{0}\left(S_{i}^{t}-S_{i}^{0}\right) \\
& +Q^{0} \sum_{i}\left(I_{i}^{t}-I_{i}^{0}\right) S_{i}^{0}
\end{aligned}
$$




$$
\begin{aligned}
& +\frac{1}{2}\left(Q^{t}-Q^{0}\right) \sum_{i}\left(I_{i}^{0}\left(S_{i}^{t}-S_{i}^{0}\right)+S_{i}^{0}\left(I_{i}^{t}-I_{i}^{0}\right)\right) \\
& +\frac{1}{2} \sum_{i}\left(S_{i}^{t}-S_{i}^{0}\right)\left(I_{i}^{0}\left(Q^{t}-Q^{0}\right)+Q^{0}\left(I_{i}^{t}-I_{i}^{0}\right)\right) \\
& +\frac{1}{2} \sum_{i}\left(I_{i}^{t}-I_{i}^{0}\right)\left(S_{i}^{0}\left(Q^{t}-Q^{0}\right)+Q^{0}\left(S_{i}^{t}-S_{i}^{0}\right)\right) \\
& +\left(Q^{t}-Q^{0}\right) \sum_{i}\left(I_{i}^{t}-I_{i}^{0}\right)\left(S_{i}^{t}-S_{i}^{0}\right)
\end{aligned}
$$

The base values in this analysis follow Laspeyres index method, i.e. the initial year values were used as a base. The computation of the effects was done for the two given periods by additive decomposition. As the equations above suggest, the resulting effects are in absolute values (Mtoe ${ }^{9}$ ). For comparison purposes, the relative values are used as the $\%$ amount of the base year energy use.

\section{Energy intensity convergence}

To briefly analyze the evolution of energy intensity between the two groups, beta and sigma convergence in energy intensity is examined (on the subject of convergence see e.g. Barro and Sala-i-Martin (1992)).

There is an evidence for beta convergence if negative (and significant) coefficient is obtained when regressing the growth rates on the initial levels. In other words, the initial level of energy intensity plays its role in how fast is the lowering of the energy intensity. If beta convergence is present, with higher levels of initial energy intensity (as we expect, and also can find in most of the new member countries) we should observe a faster rate by which the energy intensity is reduced.

The following model was estimated for each group (using panel data model where the individual effects $\alpha_{i}$ are treated as random and with GLS estimator exploiting the structure of the error covariance matrix):

$$
\begin{gathered}
\log I_{i}^{t}=\alpha_{i}+(1-\beta) \log I_{i}^{t-1}+u_{i}^{t} \\
\log \frac{I_{i}^{t}}{I_{i}^{t-1}}=\alpha_{i}-\beta \log I_{i}^{t-1}+u_{i}^{t}
\end{gathered}
$$

The evidence for the sigma convergence is found if the characteristics of the distribution lead to a lower dispersion. Sala-i-Martin describes when examining the evolution of income: "Sigma convergence studies how the distribution of income evolves over time and beta convergence studies the mobility of income within the same distribution" (Sala-i-Martin (1996)). In other words, if sigma convergence is present, we

\footnotetext{
${ }^{9}$ Millions of tonnes of oil equivalent, in IEA definition (the amount of energy of burning one tonne of crude oil, approximately $41.868 \mathrm{GJ}$ or $11.63 \mathrm{MWh}$ )
} 
should be able to observe energy intensities becoming "more similar" in these groups. Also, the beta convergence is a necessary but not a sufficient condition for the sigma convergence.

Sigma convergence is examined by evolution of the standard deviation of the logarithms of energy intensity and the coefficient of variation of energy intensity ${ }^{10}$. Decrease of these two measures over time is interpreted as an evidence for sigma convergence.

\section{Energy consumption}

In order to describe changes in energy consumption, a model of a complete decomposition with three factors described above is utilized. In this paper, the activity effect captures the additional energy demand of increased economic activity, structure effect the additional demand due to the shifts between the economic "significance" of countries and intensity effect the additional (usually negative) use due to the changes of energy intensity.

Figure 1: Decomposition effects, 1990-2008

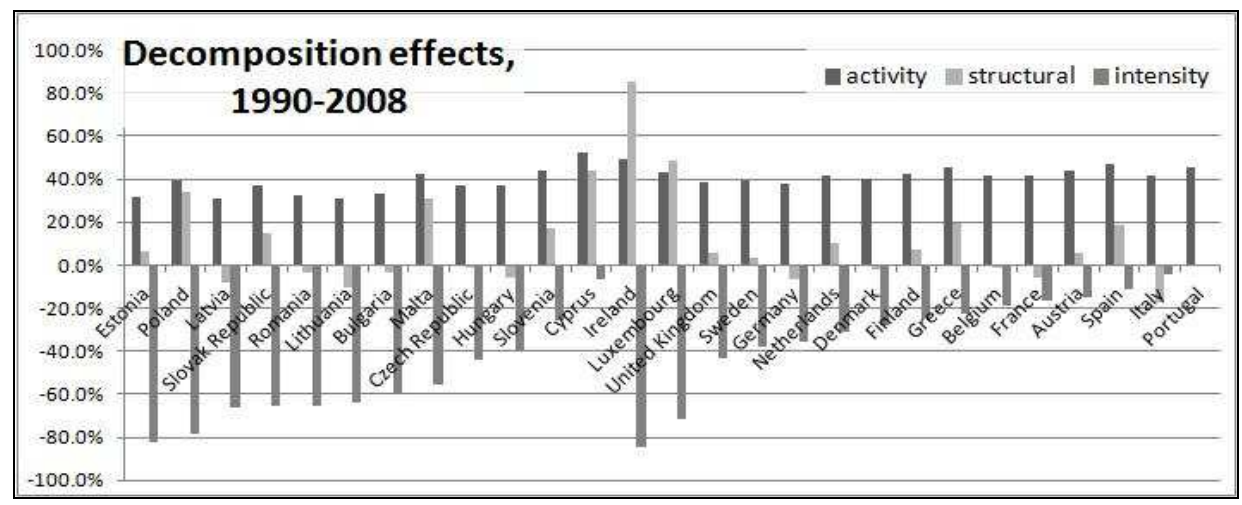

The results of decomposition analysis are summarized in

Table 1. With the exception of Germany ${ }^{11}$, all old member countries showed a positive increase in energy use (in other words, the combined effects summed to positive change). On the contrary, new member countries with the exception of Cyprus, Malta and Slovenia, showed decrease in energy use. ${ }^{12}$

\footnotetext{
${ }^{10}$ Decrease of the measures over time is interpreted as an evidence for convergence, for the new member countries, the continuous decrease can be found from 1996 onwards

${ }^{11}$ Note, however, that this probably illustrates ambiguity of Germany after reunification - while the Western part is clearly in the pattern with the original "old" member countries, the Eastern part burdened by the socialist heritage is more akin to the "new" member countries. Nonetheless, due to lack of data, it is impossible to distinguish this more clearly in the analysis.

${ }^{12}$ Again, it is worth noting the intra-group heterogeneity of new member countries (e.g. by IMF classification, the status of "advanced economies" only applies to Cyprus, Czech Republic, Malta, Slovenia and Slovakia)
} 
Table 1: Activity, structural and intensity effect, absolute and relative values, 1990-2008

\begin{tabular}{|c|c|c|c|c|c|c|c|c|}
\hline & \multicolumn{2}{|c|}{ Activity effect } & \multicolumn{2}{|c|}{ Structural effect } & \multicolumn{2}{|c|}{ Intensity effect } & \multicolumn{2}{|c|}{ Actual change } \\
\hline & Mtoe & $\%$ & Mtoe & $\%$ & Mtoe & $\%$ & Mtoe & $\%$ \\
\hline European Union & 644.7 & $39.4 \%$ & 0.0 & $0.0 \%$ & -529.0 & $-32.4 \%$ & 115.7 & $7.1 \%$ \\
\hline Austria & 10.8 & $43.7 \%$ & 1.4 & $5.6 \%$ & -3.7 & $-15.1 \%$ & 8.5 & $34.2 \%$ \\
\hline Belgium & 20.1 & $41.6 \%$ & -0.6 & $-1.3 \%$ & -9.2 & $-19.1 \%$ & 10.3 & $21.3 \%$ \\
\hline Bulgaria & 9.5 & $33.4 \%$ & -1.1 & $-3.8 \%$ & -17.2 & $-60.4 \%$ & -8.8 & $-30.8 \%$ \\
\hline Cyprus & 0.7 & $52.5 \%$ & 0.6 & $43.8 \%$ & -0.1 & $-6.3 \%$ & 1.2 & $90.0 \%$ \\
\hline Czech Republic & 18.0 & $37.0 \%$ & -0.8 & $-1.6 \%$ & -21.4 & $-43.9 \%$ & -4.1 & $-8.5 \%$ \\
\hline Denmark & 6.9 & $39.8 \%$ & -0.3 & $-1.9 \%$ & -4.9 & $-28.3 \%$ & 1.7 & $9.6 \%$ \\
\hline Estonia & 3.1 & $31.9 \%$ & 0.6 & $6.5 \%$ & -7.8 & $-82.0 \%$ & -4.2 & $-43.6 \%$ \\
\hline Finland & 12.0 & $42.2 \%$ & 2.0 & $7.1 \%$ & -7.1 & $-25.1 \%$ & 6.9 & $24.2 \%$ \\
\hline France & 92.3 & $41.2 \%$ & -13.4 & $-6.0 \%$ & -36.4 & $-16.2 \%$ & 42.6 & $19.0 \%$ \\
\hline Germany & 131.6 & $37.5 \%$ & -23.7 & $-6.7 \%$ & -124.1 & $-35.3 \%$ & -16.1 & $-4.6 \%$ \\
\hline Greece & 9.7 & $45.1 \%$ & 4.1 & $19.1 \%$ & -4.8 & $-22.3 \%$ & 9.0 & $41.9 \%$ \\
\hline Hungary & 10.6 & $37.0 \%$ & -1.6 & $-5.6 \%$ & -11.2 & $-39.1 \%$ & -2.2 & $-7.7 \%$ \\
\hline Ireland & 4.9 & $49.3 \%$ & 8.5 & $85.1 \%$ & -8.4 & $-84.4 \%$ & 5.0 & $50.0 \%$ \\
\hline Italy & 60.7 & $41.4 \%$ & -24.7 & $-16.9 \%$ & -6.5 & $-4.4 \%$ & 29.5 & $20.1 \%$ \\
\hline Latvia & 2.5 & $31.2 \%$ & -0.6 & $-8.1 \%$ & -5.2 & $-66.0 \%$ & -3.4 & $-42.9 \%$ \\
\hline Lithuania & 5.0 & $31.1 \%$ & -1.7 & $-10.5 \%$ & -10.3 & $-63.7 \%$ & -6.9 & $-43.0 \%$ \\
\hline Luxembourg & 1.5 & $43.4 \%$ & 1.7 & $48.6 \%$ & -2.4 & $-71.3 \%$ & 0.7 & $20.7 \%$ \\
\hline Malta & 0.3 & $42.0 \%$ & 0.2 & $31.3 \%$ & -0.4 & $-55.5 \%$ & 0.1 & $17.8 \%$ \\
\hline Netherlands & 27.5 & $41.8 \%$ & 6.9 & $10.5 \%$ & -20.3 & $-31.0 \%$ & 14.0 & $21.3 \%$ \\
\hline Poland & 40.3 & $39.1 \%$ & 35.0 & $34.0 \%$ & -80.6 & $-78.1 \%$ & -5.2 & $-5.1 \%$ \\
\hline Portugal & 7.6 & $45.2 \%$ & -0.1 & $-0.7 \%$ & 0.0 & $-0.3 \%$ & 7.4 & $44.3 \%$ \\
\hline Romania & 20.2 & $32.4 \%$ & -2.4 & $-3.8 \%$ & -40.7 & $-65.4 \%$ & -22.9 & $-36.7 \%$ \\
\hline Slovak Republic & 7.8 & $36.7 \%$ & 3.1 & $14.5 \%$ & -14.0 & $-65.4 \%$ & -3.0 & $-14.2 \%$ \\
\hline Slovenia & 2.5 & $44.1 \%$ & 1.0 & $16.9 \%$ & -1.5 & $-25.5 \%$ & 2.0 & $35.5 \%$ \\
\hline Spain & 42.2 & $46.9 \%$ & 16.5 & $18.3 \%$ & -10.0 & $-11.1 \%$ & 48.7 & $54.1 \%$ \\
\hline Sweden & 18.5 & $39.2 \%$ & 1.7 & $3.5 \%$ & -17.8 & $-37.7 \%$ & 2.4 & $5.1 \%$ \\
\hline United Kingdom & 79.6 & $38.7 \%$ & 11.2 & $5.4 \%$ & -88.3 & $-42.9 \%$ & 2.5 & $1.2 \%$ \\
\hline
\end{tabular}

All countries show positive activity effect, mostly in a rather narrow distribution when compared to other effects, however, the average activity effect of old member countries is about 1.13 times higher. This means that the increase of overall economic activity is more pronounced in the old member states.

The structure effect is highly diversified within each group, with differences as large as $43.8 \%$ (percentage of the initial year energy use) for Cyprus and $-10.5 \%$ for Lithuania 
among new member countries, and $85.1 \%$ of Ireland or $48.6 \%$ of Luxembourg, and $16.9 \%$ and $-6.7 \%$ of Italy and Germany, respectively, among old member countries. The change in energy use explained by this effect shows a relative increase of significance in the structure, if the energy intensities and overall economic activity were fixed.

As for the intensity effect, with the exception of a single country (Cyprus, $-6.1 \%$ ), the rest of the group of new member countries achieved significant reductions, on average $58.6 \%$ (Cyprus not included), with values as high as $-82 \%$ for Estonia and $-78 \%$ for Poland. ${ }^{13}$ Among the old member countries, the average intensity effect was $-29.6 \%$, the poorest result being achieved by Portugal (-0.3\%) and the best results by Ireland ($84.4 \%)$ and Luxembourg (-71.3\%). Given the "focus" of the Luxembourg and Ireland on the services with high added value like banking and $\mathrm{ICT}^{14}$, the last results are not as surprising.

Table 2 presents results of equality of means tests and equality of variances for individual effects. We can conclude that there is a difference in magnitudes of the activity effect and the intensity effect, which are big enough to affect the overall change. The only observable difference in the variability is for the activity effect, which is higher for the old member countries. However, given the distribution of the activity effect, the economic activity is projected more into the old member countries than into the new member countries.

Table 2: Difference of means and variance ratio tests between new and old member countries, by effects, 1990/2008)

\begin{tabular}{|l|c|c|c|c|}
\hline \multirow{2}{*}{} & \multicolumn{2}{|c|}{ Difference of means $=0$} & \multicolumn{2}{c|}{ Variance ratio = 1 } \\
\cline { 2 - 5 } & Test statistics & $\mathrm{p}$-value & Test statistics & $\mathrm{p}$-value \\
\hline Activity effect & -2.70166 & 0.01221 & 3.95146 & 0.01814 \\
\hline Structural effect & -0.205992 & 0.8385 & 1.88266 & 0.2967 \\
\hline Intensity effect & -2.84077 & 0.0045 & 1.09806 & 0.8906 \\
\hline Actual change & -2.19032 & 0.0285 & 5.01598 & 0.006038 \\
\hline
\end{tabular}

The results show that in the period of 1990-2008, despite the difference in the magnitudes, the development of activity effect was (in relative terms) rather similar in all member countries amounting to the total of 120.5 and 525.9 megatons of oil

${ }^{13}$ Then again, if we take a look on the actual energy consumption numbers in these countries (103.1 Mtoe in the base year and 97.9 Mtoe in the year 2008 for Poland, and 9.6 Mtoe / 5.4 Mtoe for Estonia) we can rather observe how inefficient the former ways of production (energy intensities are still 2.3 times (Poland) and 3.2 times (Estonia) higher than the EU-27 average in 2008)

${ }^{14}$ It is worth mentioning that due to the (small) absolute size of the country energy consumption in these cases (3.4 Mtoe in Luxembourg and 10 Mtoe in Ireland in the base year), all individual changes leading to higher energy efficiency (lower energy intensity) will be necessarily more likely to affect the country's position than in case of the large countries (the otherwise identical, say "moderate size firm", e.g. newly operating bank, even when achieving exactly the same results, will represent greater share on the indicators of a given country in "small countries") 
equivalent in new and old member countries, respectively. Total structural effect was highly diversified in both groups, but its cumulative size did not change the relative importance of each group very much. Per group it amounted to 32.4 megatons in the new member countries, and -8.9 megatons in the old member countries. In other words, the significance of the new member countries as a whole increased, but it was not a result of any universal pattern. The intensity effect was the most significant effect for the new member countries, amounting to the total of -210.3 in new and - 344 megatons in old member countries. The overall change in the new member countries (especially if not accounting for "atypical" new member countries like Cyprus, Malta and Slovenia) was much more pronounced in new member countries, and the variability of the intensity effect in both groups was similar.

My initial hypothesis, that there is a different development between the two groups measured by the aforementioned three effects is therefore supported by the results. The activity effect was the most significant effect in the old member countries, the primary reason for the increase being energy use. While it was on average lower in the new member countries, its development within the period followed a similar pattern in both groups. Therefore, energy intensity effect, significantly reducing the energy demands of increased economic activity (in case of new member countries even outweighing the other effects) was the main diversifying factor between the groups in the period 19902008.

Given these results, it is therefore worth examining the second hypothesis, i.e. whether there is an observable convergence in energy efficiency between the new and old member countries.

\section{Energy intensity}

In the period of 1990-2009, the GDP of the EU-27 countries (measured in constant USD of the year 2000) has increased by USD 3094.7 billion, or by $45.4 \%$, while the energy use ${ }^{15}$ has increased only by 115.6 megatons of oil equivalent (i.e. by $7.1 \%$ ). This indicates that a significant change in the energy efficiency and therefore in the intensity indicator has taken place - on average the energy intensity has been reduced by more than $30 \%$, which was mainly due to lowering energy consumption in new member countries. The overview of the basic data in the selected group of countries is provided in Table 3.

As the overall numbers suggest, there is a difference in behavior between the two groups. While the average growth rate of GDP was $2.21 \%$ and $1.96 \%$ in old and new member countries respectively, the growth rates of energy use accounted to $0.79 \%$ in the old, and $-0.91 \%$ in the new member countries.

As the Table 4 shows, the new member countries increased their share on total GDP by 0.7 p.p., while reducing their energy use by 4.6 p.p. in the period 1990-2008. The variance ratio test also indicates that variability of energy intensity within the groups

\footnotetext{
${ }^{15}$ Energy use refers to use of primary energy before transformation to other end-use fuels, which is equal to indigenous production plus imports and stock changes, minus exports and fuels supplied to ships and aircraft engaged in international transport. Primary energy consumption is calculated as the sum of the gross inland consumption of energy from solid fuels, oil, gas, nuclear and renewable sources.
} 
between the years 1990 and 2008 changed only in the new member countries. We can therefore observe that there was a different development in energy intensity development between the new and the old member countries.

The results displayed in the Table 5 indicate that there is an evidence for beta convergence in energy intensity in the EU-27. Further estimation for individual groups shows that this is the result of beta convergence of the new member countries. The estimated coefficients are $1.58 \%$ and $1.78 \%$ (i.e. with $1 \%$ increase in the energy intensity level we can expect the additional $1.58 \%$ or $1.78 \%$ of negative growth in energy intensity indicator) for EU-27 and the new member countries respectively (even though the explanatory power of these very simple models is often rather low, especially if the heterogeneity in energy intensity of the groups is not captured very well by the simple division). ${ }^{16}$

Table 3: overview of GDP and energy use in 1990 and 2008

\begin{tabular}{|c|c|c|c|c|c|c|c|c|c|}
\hline \multirow[t]{2}{*}{$\begin{array}{l}\text { Country } \\
\text { Name }\end{array}$} & \multicolumn{2}{|c|}{$\begin{array}{c}\text { GDP } \\
\text { (billions of } \\
\text { constant } 2000 \\
\text { US\$) }\end{array}$} & & \multicolumn{2}{|c|}{$\begin{array}{c}\text { Energy use }^{17} \\
\text { (MTOE) }\end{array}$} & & \multicolumn{2}{|c|}{$\begin{array}{c}\text { Energy } \\
\text { intensities } \\
\text { (toe/thousand of } \\
\text { constant } 2000 \\
\text { US\$)) }\end{array}$} & \multirow[b]{2}{*}{$\begin{array}{c}\text { Relative } \\
\text { change }\end{array}$} \\
\hline & 1990 & 2008 & $\begin{array}{c}\text { Relative } \\
\text { change }\end{array}$ & 1990 & 2008 & $\begin{array}{c}\text { Relative } \\
\text { change }\end{array}$ & 1990 & 2008 & \\
\hline EU-27 & 6813.9 & 9908.6 & $45.4 \%$ & 1635.1 & 1750.7 & $7.1 \%$ & 0.24 & 0.18 & $-26.4 \%$ \\
\hline Austria & 149.0 & 227.2 & $52.5 \%$ & 24.8 & 33.2 & $34.2 \%$ & 0.17 & 0.15 & $-12.0 \%$ \\
\hline Belgium & 186.5 & 268.2 & $43.8 \%$ & 48.3 & 58.6 & $21.3 \%$ & 0.26 & 0.22 & $-15.6 \%$ \\
\hline Bulgaria & 14.6 & 20.3 & $39.3 \%$ & 28.6 & 19.8 & $-30.8 \%$ & 1.96 & 0.97 & $-50.3 \%$ \\
\hline Cyprus & 6.2 & 12.3 & $98.5 \%$ & 1.4 & 2.6 & $90.0 \%$ & 0.22 & 0.21 & $-4.3 \%$ \\
\hline $\begin{array}{c}\text { Czech } \\
\text { Republic }\end{array}$ & 55.3 & 79.2 & $43.1 \%$ & 48.8 & 44.6 & $-8.5 \%$ & 0.88 & 0.56 & $-36.0 \%$ \\
\hline Denmark & 123.9 & 177.0 & $42.8 \%$ & 17.3 & 19.0 & $9.6 \%$ & 0.14 & 0.11 & $-23.3 \%$ \\
\hline Estonia & 6.0 & 9.4 & $57.0 \%$ & 9.6 & 5.4 & $-43.6 \%$ & 1.60 & 0.57 & $-64.1 \%$ \\
\hline Finland & 99.3 & 153.8 & $54.9 \%$ & 28.4 & 35.3 & $24.2 \%$ & 0.29 & 0.23 & $-19.8 \%$ \\
\hline France & 1091.6 & 1504.1 & $37.8 \%$ & 223.9 & 266.5 & $19.0 \%$ & 0.21 & 0.18 & $-13.6 \%$ \\
\hline Germany & 1543.2 & 2097.7 & $35.9 \%$ & 351.4 & 335.3 & $-4.6 \%$ & 0.23 & 0.16 & $-29.8 \%$ \\
\hline Greece & 99.6 & 169.6 & $70.2 \%$ & 21.4 & 30.4 & $41.9 \%$ & 0.22 & 0.18 & $-16.7 \%$ \\
\hline
\end{tabular}

\footnotetext{
${ }^{16}$ Note the development of energy intensity in Cyprus, Malta and Slovenia that would, however, fit very well with development of the old member countries

${ }^{17}$ Energy use refers to use of primary energy before transformation to other end-use fuels, which is equal to indigenous production plus imports and stock changes, minus exports and fuels supplied to ships and aircraft engaged in international transport.

Primary energy consumption is calculated as the sum of the gross inland consumption of energy from solid fuels, oil, gas, nuclear and renewable sources.
} 


\begin{tabular}{|c|c|c|c|c|c|c|c|c|c|}
\hline Hungary & 44.0 & 60.5 & $37.4 \%$ & 28.7 & 26.5 & $-7.7 \%$ & 0.65 & 0.44 & $-32.8 \%$ \\
\hline Ireland & 48.5 & 135.4 & $179.0 \%$ & 10.0 & 15.0 & $50.0 \%$ & 0.21 & 0.11 & $-46.2 \%$ \\
\hline Italy & 937.6 & 1171.8 & $25.0 \%$ & 146.6 & 176.0 & $20.1 \%$ & 0.16 & 0.15 & $-3.9 \%$ \\
\hline Latvia & 10.4 & 13.7 & $31.7 \%$ & 7.9 & 4.5 & $-42.9 \%$ & 0.75 & 0.33 & $-56.7 \%$ \\
\hline Lithuania & 15.9 & 20.3 & $27.9 \%$ & 16.1 & 9.2 & $-43.0 \%$ & 1.02 & 0.45 & $-55.5 \%$ \\
\hline Luxembourg & 12.4 & 27.5 & $121.4 \%$ & 3.4 & 4.1 & $20.7 \%$ & 0.28 & 0.15 & $-45.5 \%$ \\
\hline Malta & 2.4 & 4.5 & $92.1 \%$ & 0.7 & 0.8 & $17.8 \%$ & 0.29 & 0.18 & $-38.6 \%$ \\
\hline Netherlands & 282.0 & 450.1 & $59.6 \%$ & 65.7 & 79.7 & $21.3 \%$ & 0.23 & 0.18 & $-24.0 \%$ \\
\hline Poland & 118.0 & 237.7 & $101.4 \%$ & 103.1 & 97.9 & $-5.1 \%$ & 0.87 & 0.41 & $-52.9 \%$ \\
\hline Portugal & 87.5 & 126.5 & $44.6 \%$ & 16.7 & 24.2 & $44.3 \%$ & 0.19 & 0.19 & $-0.2 \%$ \\
\hline Romania & 44.0 & 61.2 & $39.1 \%$ & 62.3 & 39.4 & $-36.7 \%$ & 1.42 & 0.64 & $-54.5 \%$ \\
\hline $\begin{array}{r}\text { Slovak } \\
\text { Republic }\end{array}$ & 27.5 & 46.5 & $68.7 \%$ & 21.3 & 18.3 & $-14.2 \%$ & 0.77 & 0.39 & $-49.1 \%$ \\
\hline Slovenia & 16.6 & 27.9 & $67.7 \%$ & 5.7 & 7.7 & $35.5 \%$ & 0.34 & 0.28 & $-19.2 \%$ \\
\hline Spain & 440.6 & 740.9 & $68.2 \%$ & 90.1 & 138.8 & $54.1 \%$ & 0.20 & 0.19 & $-8.4 \%$ \\
\hline Sweden & 201.0 & 302.4 & $50.4 \%$ & 47.2 & 49.6 & $5.1 \%$ & 0.23 & 0.16 & $-30.1 \%$ \\
\hline $\begin{array}{c}\text { United } \\
\text { Kingdom }\end{array}$ & 1150.3 & 1763.1 & $53.3 \%$ & 205.9 & 208.5 & $1.2 \%$ & 0.18 & 0.12 & $-34.0 \%$ \\
\hline \multicolumn{3}{|l|}{ Average } & $60.3 \%$ & & & $10.0 \%$ & & & $-30.8 \%$ \\
\hline \multicolumn{3}{|c|}{$\begin{array}{l}\text { Average for new member } \\
\text { countries only }\end{array}$} & $58.7 \%$ & & & $-7.4 \%$ & & & $-42.8 \%$ \\
\hline \multicolumn{3}{|c|}{$\begin{array}{l}\text { Average for old member countries } \\
\text { only }\end{array}$} & $62.6 \%$ & & & $24.2 \%$ & & & $-21.5 \%$ \\
\hline
\end{tabular}

Table 4: GDP and energy use shares in 1990 and 2008

\begin{tabular}{|c|c|c|c|c|c|c|}
\hline & \multicolumn{2}{|c|}{ New member countries } & \multicolumn{2}{|c|}{$\begin{array}{l}\text { Old member } \\
\text { countries }\end{array}$} & \multirow{2}{*}{\multicolumn{2}{|c|}{$\begin{array}{c}\text { Increase in } \% \text { share of new } \\
\text { member countries }\end{array}$}} \\
\hline & 1990 & 2008 & 1990 & 2008 & & \\
\hline GDP share of the group & $5.3 \%$ & $6.0 \%$ & $94.7 \%$ & $94.0 \%$ & \multicolumn{2}{|c|}{$0.7 \%$} \\
\hline Energy use share of the group & $20.4 \%$ & $15.8 \%$ & $79.6 \%$ & $84.2 \%$ & \multicolumn{2}{|c|}{$-4.6 \%$} \\
\hline Average energy intensity & 0.90 & 0.45 & 0.21 & 0.16 & \multicolumn{2}{|c|}{$\begin{array}{l}\text { Variance ratio test }{ }^{18}(\mathrm{p}- \\
\text { value })\end{array}$} \\
\hline \multirow{2}{*}{ Standard deviation } & \multirow{2}{*}{0.5334} & \multirow{2}{*}{0.21756} & \multirow{2}{*}{0.042159} & \multirow{2}{*}{0.035782} & New & Old \\
\hline & & & & & 0.006041 & 0.5475 \\
\hline
\end{tabular}

\footnotetext{
${ }^{18} \mathrm{H} 0$ : the ratio of the two standard deviations is unity (against the two-tailed alternative).
} 
Using the similar non-parametric measures of sigma-convergence as Ezcurra (2007), i.e. evolution of standard deviation of the logarithms and the coefficient of variation of energy intensity ${ }^{19}$ and the distribution characteristics), I conclude there is an evidence for sigma convergence in the group of the new member countries and in total EU27, as confirmed also by the results of variance ratio tests.

\section{Table 5: beta convergence results, 1990-2008}

\begin{tabular}{|c|c|c|c|c|c|c|c|c|c|}
\hline & \multicolumn{2}{|c|}{ New member countries } & \multicolumn{3}{c|}{ Old member countries } & \multicolumn{3}{c|}{ EU-27 countries } \\
\cline { 2 - 10 } & value & $\begin{array}{c}\mathrm{t}- \\
\text { statistic }\end{array}$ & $\begin{array}{c}\mathrm{p}- \\
\text { value }\end{array}$ & value & $\begin{array}{c}\mathrm{t}- \\
\text { statistic }\end{array}$ & $\begin{array}{c}\mathrm{p}- \\
\text { value }\end{array}$ & value & $\begin{array}{c}\mathrm{t}- \\
\text { statistic }\end{array}$ & $\begin{array}{c}\mathrm{p}- \\
\text { value }\end{array}$ \\
\hline Constant & -0.0423 & -10.14 & 0 & -0.01261 & -0.9568 & 0.3395 & -0.0409 & -10.46 & 0 \\
\hline Beta & -0.0178 & -3.255 & 0.0013 & 0.0009 & 0.1222 & 0.9028 & -0.0158 & -5.574 & 0 \\
\hline $\mathrm{N}$ & \multicolumn{3}{|c|}{220} & \multicolumn{3}{|c|}{285} & \multicolumn{3}{c|}{524} \\
\hline
\end{tabular}

Figure 2: Standard deviations of the logarithms and the coefficients of variation for energy intensity

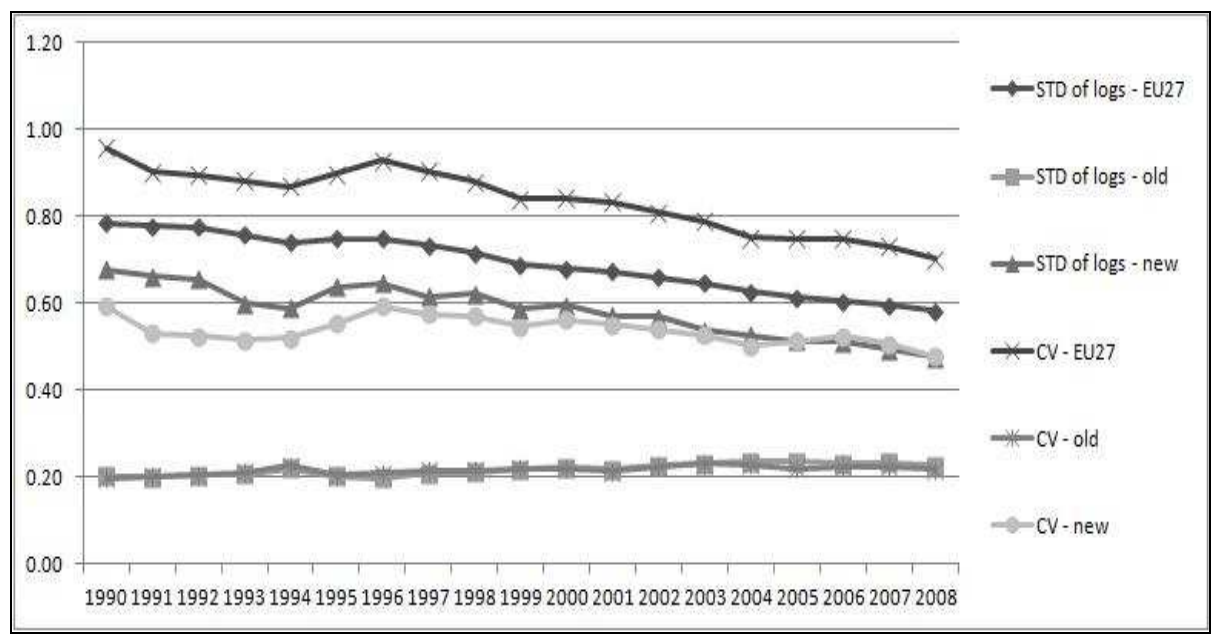

There is no evidence for sigma convergence among the old member countries.

\footnotetext{
${ }^{19}$ Decrease of the measures over time is interpreted as an evidence for convergence, for the new member countries, the continuous decrease can be found from 1996 onwards.
} 
Figure 3: Frequency distribution of energy intensity in the old and the new member countries
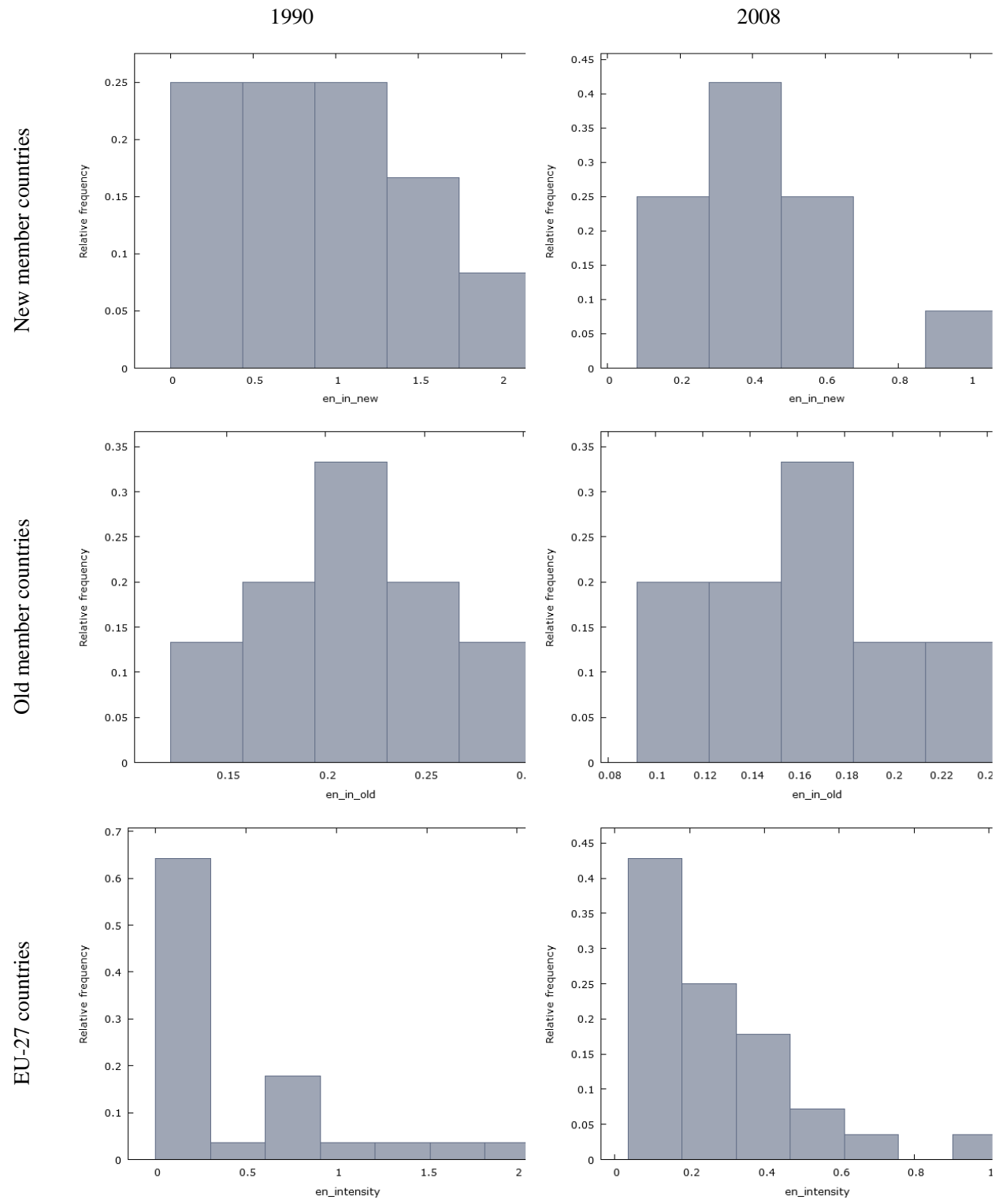

The results of this chapter support my additional hypothesis that the new member countries show sigma convergence (note the beta convergence is necessary (but not sufficient) condition for the sigma convergence), i.e. the energy efficiency in the new member countries is getting more and more similar (see Figure 3) to the levels of "more developed" EU-15 countries that were not hampered by the burden of centrally planned 
economies and resulting economic damages. Nonetheless, this rate is not very fast and the fact that the energy intensity still remains much higher in the new member states indicates consequences of the diversifying factors have not diminished yet. ${ }^{20}$

While there is more or less common downward trend, the average energy intensity remains almost three times higher in the new member countries (Cyprus, Malta and Slovenia, however, exhibits levels and development more closer to those of old member countries; it should be noted though that due to their size (their combined GDP amounts to approx. $0.45 \%$ of the EU-27), these countries exhibit higher sensitivity to any individual activities within the countries). It should be said though that a more complex analysis of the underlying characteristics of the energy intensity is beyond the scope of this paper, and may be a subject of further work.

\section{Conclusion}

The results verify my initial hypothesis that there is an observable difference between the decomposed effects of the new and the old member states.

Decomposition of energy consumption shows that energy intensity effect, significantly reducing the energy demands of an increased economic activity (in case of new member countries even outweighing the other effects) was the main diversifying factor between the groups (in the period 1990-2008). The activity effect, despite being the most substantial effect in the old member countries and the main agent behind their increased energy use, follows relatively similar development in both groups, but with the new member countries slightly lagging behind the EU-15 countries.

While the new member countries did show almost twice as big reduction in their energy intensity (compared to the old member countries), it is necessary to keep in mind that this reduction was affected by their high starting values; replacing of the outdated communist era technology thus played a dominant role in this reduction. Even at the end of the examined period, energy intensity remains on average almost three times higher in the new member countries. As the activity effect is on average 1.13 times higher in the old member countries, it shows that the economic growth in the examined period was more pronounced in the old member countries. This indicates that should strict(er) energy policies be implemented to achieve the EU Convergence goal $^{21}$, in order to compensate for their lower activity, the new member countries would need even more energy efficient technologies than the old member countries. This is not only hard to imagine, but to some extent raises doubts about emphasis on stricter energy efficiency and energy savings measures (often increasing costs) as an instrument of convergence, especially if such policies are financed by increased taxes in direct or indirect form.

The most distinct results among the old member countries were the effects for Ireland and Luxembourg (both of these countries were focused on high added value services (like ICT and banking) and exhibited large economic growth rates), showing above-

\footnotetext{
${ }^{20}$ In this case, being new member state is almost identical to being post-communist, formerly centrally planned economy

${ }^{21}$ E.g. statements like: "For both Convergence and the Regional Competitiveness and Employment objectives an important ERDF priority is to stimulate energy efficiency and renewable energy production and the development of efficient energy management systems." (http://ec.europa.eu/regional_policy/archive/themes/energy/index_en.htm)
} 
average results (within the group) for each of the decomposition effects. Among the new member countries, these positions are held by Malta and surprisingly Poland, indicating the extension of their economic activities, increasing economic significance and energy intensity improvements.

The analysis of the main diversifying effect (the intensity effect) indicates that the division by the groups of the new and the old member countries is not perfect (especially concerning the non-Eastern-Bloc countries like Cyprus and Malta, showing development more close to that of old member countries). However, even this "rough" grouping shows different convergence behavior in the energy intensity. There is an evidence for sigma convergence among the new member countries. This means the distribution of energy intensities of the new member countries is getting closer to that of the old member countries. The results for the beta convergence (as a necessary condition of sigma convergence) correspond to this pattern, even though the explanatory power of the simple model used in this paper may not be very high (in further work, it might be appropriate to consider the conditional convergence). This convergence is more evident from the year 1996 onwards (the period 1990-1996 may be affected by the transition process after the collapse of the centrally planned economies). In short, the new member countries become more similar in their energy efficiency to the old member countries and the process has not stopped yet.

This supports my second hypothesis that even though there is more or less a common downward trend in all EU-27 countries, the new member countries are getting closer in their energy efficiencies to the EU-15 countries (but they are still not yet on par). While the convergence is not very fast given the fact there is no observable convergence among the EU-15 countries, it is possible that the rates of the energy intensity indicator will even out eventually. There is no evidence for either beta or sigma convergence in energy intensity among the EU-15 countries (if anything, there may be a slight indication for energy intensity divergence for the old member countries).

\section{References}

ANG, B.W., NA LIU. (2007). Energy decomposition analysis: IEA model versus other methods. Energy Policy. 35: pp. 1426-1432.

ANG, B.W., ZHANG, F. Q. (2000). A survey of index decomposition analysis in energy and environmental studies. Energy. 25: pp. 1149-1176.

BARRO, R.J., SALA-I-MARTIN, X.. (1992). Convergence. Journal of Political Economy.100, pp. 407-443.

CLEVELAND, C.J., KAUFMANN, R.K., STERN, D.I. (2000). Aggregation and the role of energy in the economy. Ecological Economics. 32, pp. 301-317

EZCURRA R. (2007). Distribution dynamics of energy intensities: a cross-country analysis. Energy Policy. 35: 5254-5259

FISHER I. (1972). The making of index numbers. 3rd ed. Boston, MA: Houghton Mifflin. 
PATTERSON, M. G. (1996). What is energy efficiency?: Concepts, indicators and methodological issues. Energy Policy 24: 377-390.

SALA-I-MARTIN, X. (1996). Regional cohesion: Evidence and theories of regional growth and convergence. European Economic Review. 40: pp. 1325-1352.

SUN, J.W. (1996). Quantitative analysis of energy consumption, efficiency and savings in the world, 1973-1990. Turku School of Economics Press, series A-4: 1996.

SUN, J.W. (1998). Changes in energy consumption and energy intensity: A complete decomposition model. Energy Economics. 20: pp. 85-100. 